Aus der Universitäts-Frauenklinik zu Zürich.

Direktor: Prof. Dr. Theodor Wyder.

\title{
Ein Fall von Geburtshindernis, bedingt durch iibermässige Dilatation der fötalen Harnblase mit gleichzeitiger Ruptur derselben.
}

Von

\author{
Dr. Paul Böhi, \\ Assistent der Klinik. \\ (Hîeryu 'Tafel XIV_XV und 3 Textfiguren.)
}

Unter den Geburtsstörungen infolge anormaler Grösse des fötalen Abdomens gehören diejenigen, welche verursacht sind durch eine Missbildung der Harnblase mit einer starken Dilatation, zu den selteneren.

Der am 12. Februar 1913 in der hiesigen Frauenklinik beobachtete Fall verdient neben der klinisehen Bedeutung deshalb noch ein besonderes Interesse, weil er, soweit die Literatur mir zugänglich war, der einzige ist, bei dem die Urinretention in der Harnblase einen so hohen Grad erreichte, dass es zu einer im Intrauterinleben entstandenen Blasenruptur kam, und weil ausserdem sich an sämtlichen Organen des Abdomens Missbildungen oder sekundäre Verändernngen fanden, die einer genauen pathologisch-anatomischen und embryologischen Entersuchung wert waren.

Im vorliegenden Fall handelt es sich um eine 23jährige Erstgebärende mit folgender Anamnese:

Vater gesund, Mutter vor 15 Jahren an Kindbettfieber gestorben. Als Kind machte Pat. Diphtherie und Masern durch. Sonst will sie nie ernstlich krank gewesen sein, speziell keine Haut-, Hals- oder Knochenerkrankungen gehabt haben.

Erste Menses mit 12 Jahren, immer regelmässig alle $3-4$. Wochen, 4 Tage dauernd, verbunden mit leichten Kreuzschmerzen. Letzte normale Periode anfangs September 1912. Anfangs Oktober trat eine drei Wochen lang dauernde, leichte, kontinuierliche Blutung ein; Mitte Dezember will Pat. noch einmal während 2 Tagen eine ziemlich profuse "Periode" gehabt haben. Erst im Januar bemerkte Pat., die bis zu dieser Zeit nicht gewusst haben will, dass sie gravid sei, eine Vergrösserung des Abdomens, die sehr rasch zunahm.

Bei ihrer Aufnahme auf den Gebärsaal am 13. Februar 1913, 3 Uhr p. m., gibt die Parturiens an, dass sie seit gestern abend kräftige, regelmässige Wehen habe, die sich in Intervallen von 5-10 Minuten gefolgt seien. Abgang von Fruchtwasser will sie nicht beobachtet haben. 
Bei der äusseren Untersuchung lässt sich folgender Status feststellen: Mittelgrosse Frau in gutem Ernährungszustand und mit etwas blasser Gesichtsfarbe. Temperatur 37,2, Puls 100. Der Thorax ist normal, die Drüsensubstanz in den Mammae gut entwickelt. Warzen, welche beiderseits auf Druck Kolostrum entleeren, prominent. Warzenhof pigmentiert. Herz und Lungen $0 . \mathrm{B}$.

Der Leib hat eine ovoide Form; der prall gespannte Uterus reicht bis dicht unter den Processus xyphoideus. Grösster Leibesumfang $101 \mathrm{ccm}$. Beim Beklopfen des Abdomens entsteht eine deutliche Fluktuation, die sich in allen Richtungen gleichmässig fortpflanzt. Auf der linken Seite, ungefähr auf Nabelhöhe, ist ein wenig beweglicher, ziemlich grosser, nicht ballotierender Teil zu fühlen. Die Herztöne sind in der Medianlinie, 2 Querfinger breit unterhalb vom Nabel, deutlich zu hören. Ihre Zahl beträgt $120-140$ pro Minute. Beckenmaasse: Sp. 26,5; Cr. 29; Tr. 30,5 ; C. ext. $20 ;$ B. U. 94.

Die innere Untersuchung ergibt folgenden Befund: Vulva ziemlich eng, Portio verstrichen, Muttermund handtellergross. Aus demselben drängt sich eine prall gespannte Blase mit dicker Vandung hervor, diebei den kräftigen Wehen bis tief in die Vagina hinabgedrückt wird. Ein vorliegender Teil in dieser stehenden Blase kann nirgends nachgewiesen werden.

Eine klare Diagnose kann vorläufig aus diesem Befund nicht gestellt werden. Man denkt zuerst an ein Hydramnion mit stark verdickten Eihäuten.

7,30 p. m.: Da die Geburt trotz der kräftigen Wehen während des ganzen Nachmittags keine Fortschritte machte, insbesondere die Blase, deren bläulichrote Kuppe bei den starken Wehen einige Male sogar in der Vulva sichtbar wurde, nicht gesprungen ist, wird eine zweite Untersuchung vorgenommen, die genau zu demselben Ergebnis führt wie die frühere.

Dabei beobachtet man, dass über dem touchierenden Finger in dem prall elastischen Tumor plötzlich ein ziemlich grosser Längsriss entsteht, jedoch ohne dass sich der Blaseninhalt entleert. Man kann nun deutlich eine Schicht von der Oberfläche des Tumors lostrennen. (Wie sich später herausstellte, handelte es sich hier um die eingerissene, durch ein subkutanes Hämatom brüchig gewordene Haut an den Bauchdecken des Fötus) vergl. Textfig. 2.

Da man aus diesen beiden Untersuchungen zur Ueberzengung kommt, dass neben der Möglichkeit des Hydramnion irgend eine Missbildungvon Seiten des Fötus vorliegen müsse, wie hochgradiger, dünnwandiger Hydrocephalus, bei dem es zu einem vollständigen Schwund der Schädelknochen gekommen ist (Haare konnten an der Oberfläche des Tumors allerdings nicht gefühlt werden), oder irgend eine cystische Neubildung, oder ein fötaler Aszites, und da man ferner den Eindruck hat, dass die Geburt spontan nicht beendigt werden könne, entschliesst man sich, diesen prall elastischen Tumor zu perforieren, indem man in den schon entstandenen Riss des vorliegenden Hautsackes mit dem Finger weiter einbohrt, bis die Wand der "Blase" platzt. Aus der so entstandenen Oeffnung entleeren sich im Strahl ca. 3 Liter einer bernsteingelben Flüssigkeit, während das Abdomen der Frau zusehends kleiner wird. Nach Abfluss des Blaseninhaltes wird zur genaueren Feststellung der Art des Geburtshindernisses noch einmal mit der Hand in die Vagina. eingegangen. Man fühlt nun deutlich die beiden kleinen Füsse des. 
Fötus, die Fersen nach rechts, die Zehen nach links gerichtet. Einige Minuten später erscheint in der Vulva die Kuppe des entleerten, sehlaffen, ca. $1 \mathrm{~cm}$ dicken, derben Hautsackes, an dessen Oberfläche deutlich Ilautporen erkennbar sind. In einem handtellergrossen, blutig imbibierten Bezirk (Partie des Hautsackes, die sich während der Geburt in den Muttermund eingestellt hat), sieht man die für einen Finger durchgängige Perforationsstelle. Nach weiteren 5 Minuten wird der Fötus in zweiter vollkommener Fusslage, gleichzeitig neben einem grossen, leeren Hautsack ausgestossen. Unmittelbar darauf folgt die Plazenta spontan. Eihäute vollständig, Kontraktion des Uterus gut. Nach der Geburt sieht man beim Fötus in der Herzgegend deutlich Pulsationen, die jedoch nach wenigen Minuten langsamer werden und allmählich ganz verschwinden.

Wochenbettsverlauf rollkommen normal, keine Temperaturen über 37 . Entlassung am 8. Tag post partum. Obgleich die Leiche des Kindes keine Anhaltspunkte für Lues zeigt, wird doch, um einen allfälligen Verdacht auf solche auszuschliessen, im hiesigen hygienischen Institut dis Wassermann'sche Reaktion ausgeführt. Das Resultat derselben ist negativ.

Was die Diagnosenstellung vor und während der Geburt anbetrifft, so war es wohl kaum möglich, von allen hier in Betracht kommenden Eventualitäten die richtige mit Bestimmtheit zu eruieren.

Da von der Kreissenden kein Abgang von Fruchtwasser beobachtet wurde, so hat man in erster Linie an ein Hydramnion gedacht. Dafür sprach auch die Fluktuation, die abnorm rasche Ausdehnung des Abdomens am Ende der Gravidität und die fehlenden Kindsbewegungen.

Wodurch die abnorme Ausdehnung des fötalen Abdomens bedingt war, ob durch einen Hydrocephalus [Verwechslung von Hydrocephalus mit Harnblase bei Merrimann (25)], ob durch Aszites oder durch eine abnorm dilatierte Harnblase, oder durch eine fötale Cystenniere oder sonst irgendwelche cystische Tumoren, konnte in unserem Falle vor der Geburt des Kindes wohl kanm entschieden werden.

Ueber die Lage und Haltung des Fötus im Uterus können wir uns, nachdem wir den Geburtsverlauf kennen, eine genaue Vorstellung machen; da die Herztöne in der Medianlinie unterhalb des Nabels deutlich gehört wurden, so muss der Rücken des Kindes unbedingt der Bauchwand direkt angelegen haben. Da ferner die rechte Seite des fötalen Abdomens sich in den Muttermund einstellte, auf der linken Seite der Mutter ein grosser Teil (Kopf) gefühlt wurde, und bei der inneren Untersuchung keine Füsse neben der prall gespannten Blase erreichbar waren, so muss das Kind in erster dorso-anteriorer Querlage, in der in Textfigur 1 
wiedergegebenen Haltung mit auf dem Thorax liegenden Armen im Uterus sich befunden haben. Nach der Perforation und Entleerung des Abdominalsackes drehte sich der Fötus aus der Querlage in eine zweite vollkommene Fusslage, in der er neben dem Hautsack ausgestossen worde.

Vom therapeutischen Standpunkte aus konnte nichts Anderes in Betracht kommen als eine operative Verkleinerung des Abdomens durch Perforation der cystischen Geschwulst bei lebendem Kind, umsomehr, als derartige missgebildete Föten nie lebensfähig sind und eine spontaue Geburt nur äusserst selten vor sich gehen kann [Magenau (16) fand bei $4 \mathfrak{\jmath}$ analogen Fällen 6 Spontangeburten und eine Uterusruptur mit Tod der Mutter.]

Nicht bei allen in der Literatur beschriebenen Fällen war die Einstellung der Frucht für einen operativen Eingriff eine so günstige wie in dem hier vorliegenden. Vor allem ist die Entwicklung des Fötus bei Kopflagen erschwert, ganz besonders, weil infolge der serösen Infiltration die Gewebe der Frucht brüchig und zerreisslich geworden sind.

So wurden in den Fällen von Vernhes (16), Gaudon (16), Depaul (16), Kristeller (16), Olshausen (23), Wolczynski (16), Ahlfeld (1), Jilden (15), Schwyzer (24), Neumann (22) und Debrunner (8) bei den Extraktionsversuchen des spontan geborenen Kopfes entweder dieser oder die unteren Extremitäten oder Kopf und eine obere Extremität ausgerissen.

Um sich Rechenschaft geben zu können über die Natur und Aetiologie der fötalen Missbildung wurde eine genaue Sektion der kindlichen Leiche ausgeführt.

\section{Sektionsprotokoll.}

Kind Bonny, geb. am 12. Februar 1913, 8 Uhr p. m., gestorben ca. 5 Minuten post partum.

Sektion am 13. 2. 13, 8 Uhr p. m. Aufbewahrung des Fötus bis zur Sektion in Sublimat.

Länge des Kindes von der Ferse bis zum Scheitel: $37 \mathrm{~cm}$. Gewicht ohne die in der Bauchhöhle enthaltene Flüssigkeit: 1300, nach Auffüllung derselben mit einer 1 prom. Sublimatlösung: $4100 \mathrm{~g}$. Die Auffüllung ist jedoch keine maximale. Kopfumfang: $23 \mathrm{~cm}$. Durchmesser: B. T. $=4,5$, B. P. 2 , M. 0. 10,5. Grösster Leibesumfang $68 \mathrm{~cm}$. Der quere Umfang des ellipsoid geformten Abdomens beträgt, dicht neben der linken Seite des fötalen Rumpfes (von der Achselhöhle bis seitlich von der linken Leistenbeuge gemessen) $44 \mathrm{~cm}$. Am Kopf und an den oberen Extremitäten besteht eine leicht ödematöse Schwellung der Haut, die an den unteren Extremitäten fehlt. Kopf in frontaler Richtung flach gedrückt, Kopfknochen auffallend weich, knorpelähnlich, übereinander 
verschiebbar, Fontanellen gross, Nähte weit. Die oberen Extremitäten sind ron der Extensoren- zur Flexorenseite leicht abgeplattet; die Fingernägel erreichen die Mitte der Endphalangen. Lanugo am Rücken und an den unteren Partien des Abdomens vorhanden. An Stelle des Thorax und des Abdomens findet sich ein grosser Hautsack, der in der Brustgegend sehr dünn und elastisch, dagegen in den seitlichen und unteren Bauchpartien sulzig, ödematös und dick ist. Auf der rechten Seite des abdominalen Hautsackes findet sich in Nabelhöhe, $14 \mathrm{~cm}$ von diesem entfernt, eine für einen Finger durchgängige Oeffnung (operativ während der Geburt gemacht) mit zerfetzten, unterminierten Rändern. Dieselbe sitzt im Zentrum eines über handtellergrossen, subkutanen Hämatoms, das sich mit seiner dunkel kirschroten Farbe scharf von der angrenzenden, sulzig ödematösen Haut absetzt; stellenweise ist die Epidermis in diesem Hämatombezirk abgelöst.

Thorax und Becken sind in der Richtung von vorn nach hinten stark abgeplattet.

Die beiden unteren Extremitäten sind nach aussen rotiert, die Füsse in maximaler Valgusstellung; dabei besteht eime starke Abplattung beider Ober- und Unterschenkel von der lateralen zur medialen Seite.

Durch die bei der Geburt angelegte Oeffnung können mit einer Pipette nur wenige ccm einer trübblutigen Flüssigkeit entleert werden. Durch den schlaffen Hautsack hindurch lassen sich folgende Organe abtasten: auffallend hoch im Epigastrium eine mittelgrosse Leber, darunter einige Konvolute ron Dünndarmschlingen; etwas tiefer auf beiden Seiten der Wirbelsäule die etwa walnussgrossen Nieren; unter der Symphyse, aus dem kleinen Becken emporsteigend, fest mit der Muskulatur der vorderen Bauchwand verwachsen, kann man einen hühnereigrossen, ovoiden Tumor durchpalpieren, der eine ziemlich derbe Konsistenz aufweist.

Die Symphyse ist sehr niedrig, der Schambogen weit; die Darmbeinschaufeln sind flach, die Distanz der Spinae iliac. ant. ist grösser, als die der Cristae, ähnlich wie beim plattrachitischen Becken höchsten Grades.

An Stelle der äusseren Genitalien konstatiert man ein nicht ganz stecknadelkopfgrosses, leicht prominentes Höckerchen. Mit der Sonde lässt sich hier keine Oeffnung nachweisen. $11 \frac{1}{2} \mathrm{~cm}$ hinter diesem Genitalhöckerchen liegt ein blind endigendes, etwa $1 \mathrm{~mm}$ weites und ebenso tiefes flaches Grübchen (Analanlage).

Um das Quantum der aus dem Abdomen abgeflossenen Flüssigkeit festzustellen, wird der Fötus auf die linke Seite gelagert und durch die im Banchsack bestehende Oeffnung eine Sublimatlösung eingegossen. Bis zur maximalen Dehnung des Sackes lassen sich etwas über 3 Liter einfüllen. Nachdem man etwas von der Flüssigkeit hat abfliessen lassen, wird die Oeffnung mit einem zirkulären Faden verschlossen und eine photographische Aufnahme gemacht (Textfig. 1 und 2).

Nach Eröfnung des Adomens wird der durch Palpation vorher erhobene Befund bestätigt:

Bauchsektion. Die untere Hälfte des Abdomens präsentiert sich als eine grosse, ovale Höhle, ausgekleidet mit einem derben, beinahe $1 / 2 \mathrm{~cm}$ dicken Peritoneum. Der Stand des Diaphragmas ist ausserordentlich hoch; die Bauchorgane sind in die Höhe gedrängt.

Leber. Masse $=8,5: 4: 2$. Am unteren und oberen linken Rande läuft die Leber in eine dünne, fast $1 \mathrm{~cm}$ breite und kaum $1 \mathrm{~mm}$ dicke 
Eigur 1.

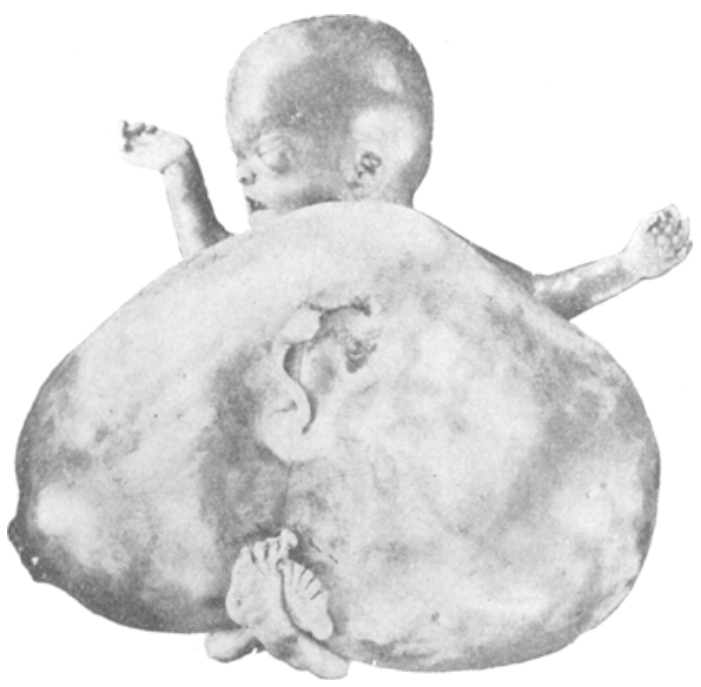

Aufnahme des Kindes von vorn, nachdem der Abdominalsack mit Flüssigkeit aufgefüllt worden ist.

Figur 2.

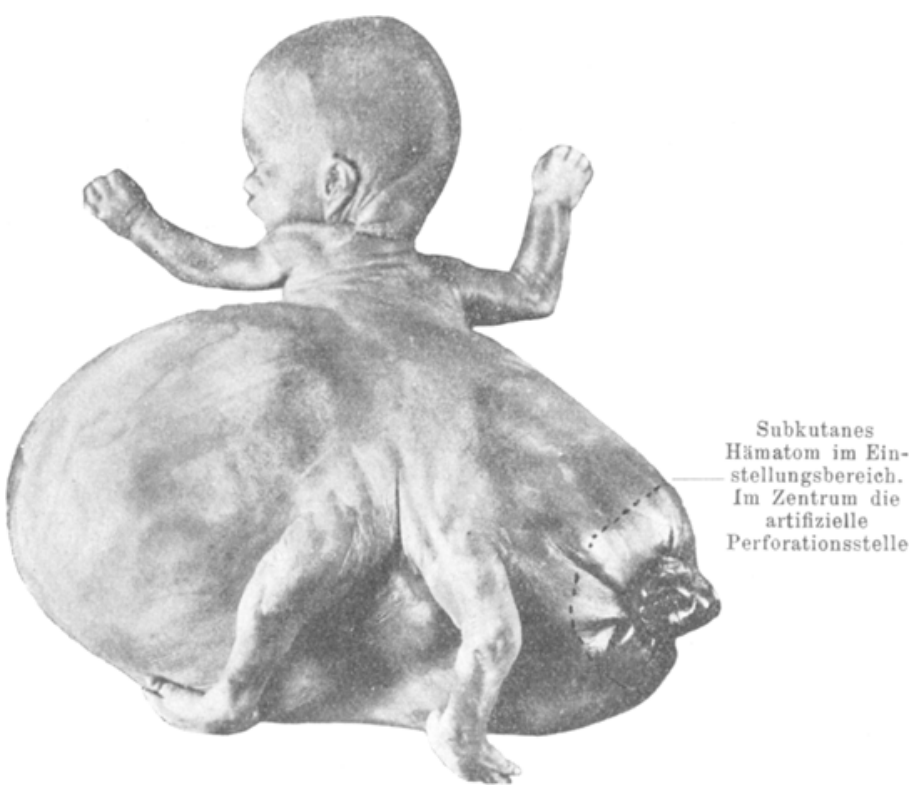

Aufnahme des Kindes von hinten. 
Lamelle aus. Die Kapsel ist nicht verdickt, die Farbe rötlichbraun, die Konsistenz ziemlich hart, die acinöse Zeichnung nicht erkennbar, dagegen sieht man die Gefässe mit ihrem weiten Lumen. Die Gallenblase ist klein, enthält grünliche Galle von zäher Konsistenz. Der Ductus choledochus ist durchgängig.

Milz. 3,2:2:1, von dunkelroter Farbe und harter Konsistenz (Stauungsmilz). Dieselbe ist in zwei Lappen geteilt.

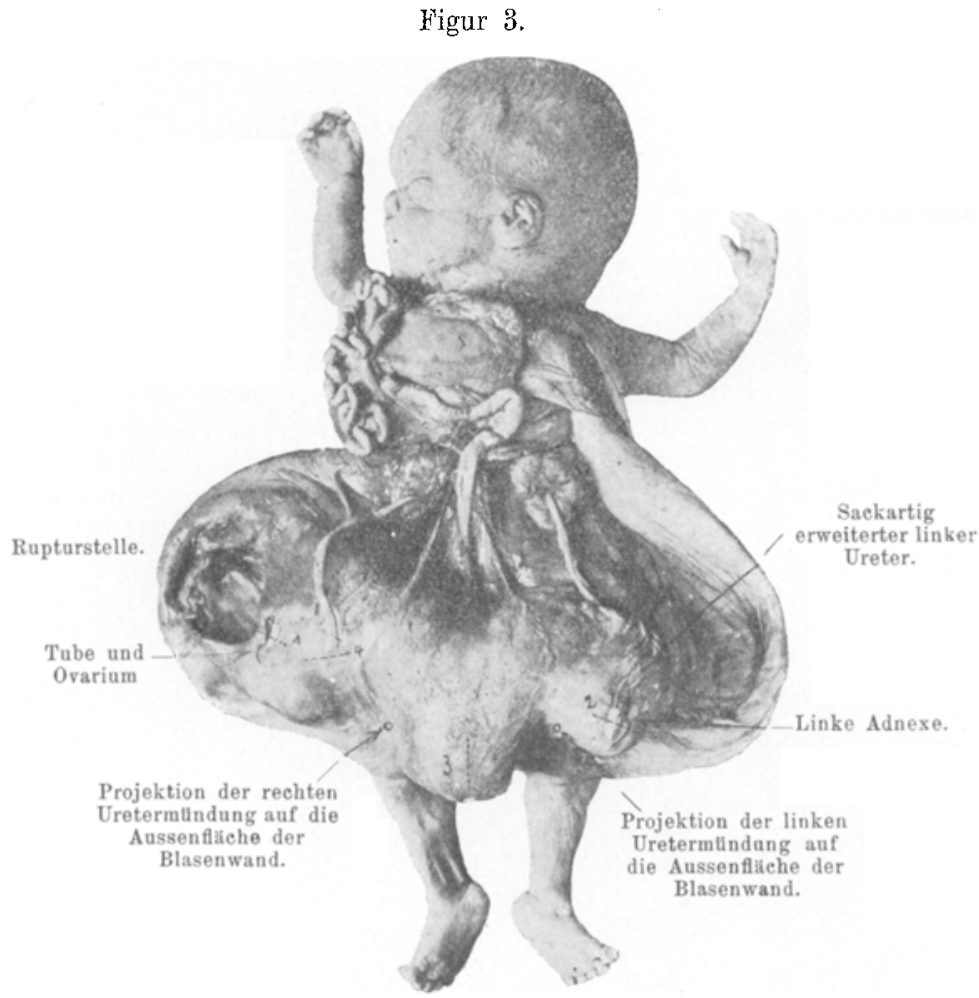

Aufnahme des Fötus mit den inneren Organen in situ. Die Schnittstellen für die mikroskopische Untersuchungen sind durch punktierte Linien angedeutet.

Magen. Darmähnlich, schmal und klein, mit kaum angedeuteter Kurvaturkrümmung und geringem Schleiminhalt. Der Darm ist dünn und zusammengefaltet, das Mesenterium kurz und derb. Der Processus vermiformis $1,2 \mathrm{~cm}$ lang und $1 \mathrm{~mm}$ dick. Im Mesenterium sind zahlreiche stecknadelkopfgrosse Lymphdrüsen; nirgends Fibrinbeläge oder Verwachsungen.

Die Nieren und Ureteren schimmern durch das oben erwähnte derbe Peritoneum hindurch. Der eingangs genannte, hühnereigrosse Tumor in der Blasengegend erweist sich als Harnblase, die nach aussen innig mit der Muskulatur des Abdomens und der Bauchhaut verwachsen ist. Das Peritoneum der Blase setzt sich unmittelbar in das derbe Bauchfell der seitlichen Abdominalwände fort. Das Kavum der Blase besteht aus 
einem mittleren, hühnereigrossen Hohlraum. Von den oberen seitlichen Ecken desselben entspringt je ein Divertikel, von denen das linke ungefähr so gross ist, wie das zentrale, das rechte fast doppelt so lang wie dieses. Die Breite der Blase beträgt $15,4 \mathrm{~cm}$, die Höhe des Mittelstückes $9 \mathrm{~cm}$ und seine Tiefe $6 \mathrm{~cm}$.

Die ganze Blase erhält dadurch eine grotesk herzförmige Gestalt. Die Wandungen der beiden seitlichen Räume gehen hinten beiderseits direkt in die Bauchwände über. Was die Struktur anbetrifft, so besitzt der mittlere Vorsprung eine sehr dicke und harte, muskulöse Wand, so dass diese zentrale Blasenpartie zuerst als derber Tumor imponierte. Die Wand der beiden seitlichen Divertikel ist hautähnlich und derb (2-4 $\mathrm{mm}$ dick).

Die unter dem Peritoneum durchschimmernden Ureteren scheinen in die seitlichen Divertikel der Harnblase einzumünden. An der lateralen Kuppe des rechten, seitlichen Blasendivertikels findet sich eine fünffrankstückgrosse Oeffnung in der Blasenwand mit glattem Rande. Diese Oeffnung stellt eine weite Kommunikation dar zwischen der erweiterten Blase und der Bauchhöhle (spontane Rupturstelle in der Blasenwand). Die Dicke der Wand an dieser Rupturstelle beträgt überall $2 \mathrm{~nm}$. Der laterale Rand präsentiert sich als ein etwa $1 \mathrm{~cm}$ hoher Gewebswulst, der auf der seitlichen Bauchwand verläuft und die Grenze zwischen rechter Blasenwand und den seitlichen vorderen Bauchdecken bildet. Im Zentrum dieser Oeffnung sieht man in der Tiefe die künstlich intra partum gemachte Perforationsstelle der Bauchdecken (siehe Textfig. 3).

Aul der Kuppe der beiden seitlichen Blasendivertikel, symmetrisch zur Medianebene gelegen, finden sich je zwei auf dem Peritoneum freiliegende Gebilde, wovon die mehr median gelegenen von oblonger Form und weissgrauer Farbe sind (Ovarien). Die Längsachse derselben verläuft parallel zur Medianebene und beträgt $1,8 \mathrm{~mm}$, die Breite $2 \mathrm{~mm}$, die Dicke ca. $1 \mathrm{~mm}$. Lateral von diesen Gebilden ist beiderseits im Abstand von 1-2 mm, parallel zu diesen, ein fadenförmiger, rötlicher Gewebsstrang, der am oberen Ende sich in Fasern auflöst und dort die erstgenannten Gebilde berührt (rudimentäre Tuben). Die rechten Adnexe sind $1 \mathrm{~cm}$ vom medianen Rande der Rupturstelle im rechten Blasendivertikel entfernt; der Abstand der beiden Ovarien von einander beträgt $13 \mathrm{~cm}$ (siehe Textfig. 3).

Nach Abpräparieren des Peritoneums von der hinteren und oberen Bauchwand bekommt man die beiden Nieren mit Nebennieren und Ureteren zu Gesicht. Die Nieren sind rosettenförmig, leicht abgeplattet; ihre Maasse betragen: rechts $3,5: 2: 0,8$, links $3,3: 2,2: 1$. Die Kapsel der rechten Niere ist als dünnes Häutchen leicht abziehbar. Die Rindensubstanz hat eine Breite von $1 / 2 \mathrm{~cm}$. Die Zeichnung der Pyramiden ist gut erkennbar, das Nierenbecken ist erweitert. Der rechte Ureter verläuft leicht bogenförmig und geschlängelt, hat vom Nierenbecken bis zum Eintritt in die Blasenwand eine Länge von $7 \mathrm{~cm}$; die Breite ist überall ungefähr gleich: $4 \mathrm{~mm}$. Nachdem man etwas unterhalb der Eintrittsstelle durch einen Querschnitt die Blasenwand eröffnet hat, konstatiert man, dass das Lumen des schlitzförmigen Ureters hier eine Breite von $7 \mathrm{~mm}$ hat.

Um den weiteren Verlauf des r. Harnleiters zu verfolgen, geht man durch diese Oenffung mit der Sonde ein und findet die Uretermündung an der Innenfläche der Blasenwand, an der Stelle, die in Textfig. 3 ein- 
gezeichnet ist. Der Verlauf des Ureters in der Blasenwand, dessen Länge etwa $4 \mathrm{~cm}$ beträgt, ist leicht bogenförmig in der Weise, dass allmählich gegen die Mündungsstelle hin eine Verengerung des Lumens eintritt. Die Mündungsstelle selbst ist eben noch für eine Millimetersonde passierbar.

Die Kapsel der linken Niere verhält sich gleich wie die der rechten. Breite der Rinde: $2-3 \mathrm{~mm}$, Pyramidenzeichnung stellenweise etwas undeutlich. In dieser Niere finden sich fünf erbsengrosse Cystchen, die unter sich keine Kommunikation zeigen und getrennt in das kleine Nierenbecken einmünden. An der Uebergangsstelle des Nierenbeckens in den Ureter hat dieser ein für eine Millimetersonde durchgängiges Lumen. In seinem weiteren Verlauf erweitert sich der Ureter dann nach und nach; $5 \mathrm{~cm}$ von der Niere entfernt hat er eine Breite von $5 \mathrm{~mm}$, an seiner Uebergangsstelle in die Blasenwand, bis zu welcher der Ureter eine Länge von $7 \mathrm{~cm}$ hat, erweitert er sich cystenartig. Auf einem Querschnitt an dieser Stelle findet man eine Breite des sehr dünnwandigen Cystensackes von $25 \mathrm{~mm}$. In dieser Breite verläuft der Ureter in der Blasenwand ebenfalls bogenförmig, und, wie rechts, allmählich sich verengernd. Unterhalb der linken Adnexe beträgt seine Breite noch $22 \mathrm{~mm}$ (mikroskopisches Bild vergl. Fig. 2, Taf. XIV). An der in Textfig. 3 eingezeichneten Mündungsstelle hat die schlitzförmige Uretermündung, die sich am Blasengrund auf der Innenfläche der Blasenwand befindet, eine Breite von $15 \mathrm{~mm}$. Die Länge dieses bogenförmigen, sackartig erweiterten Ureters von der Eintrittsstelle in die Blasenwand bis zur Mündung im Blasengrund beträgt $7 \mathrm{~cm}$.

Die Innenfläche der Blasenwand ist von weisser Farbe, lederartig und von glatter Oberfläche. Nur an der Stelle des zentralen Blasenvorsprunges ist sie etwas faltig.

In der unteren Partie des Colon transversum und der Flexura sigmoidea schimmert in dem prall gefüllten Darm das Mekonium blaugrünlich durch; das Colon transversum setzt sich spitzwinklig in die Flexura sigmoidea fort. Analwärts geht die vordere Wand des Colon sigmoideum direkt in die hintere Blasenwand über. Dieser Darmabschnitt lässt sich von der hinteren Beckenwand gut abpräparieren; hinten besteht zwischen dem Rektum und der Lendenwirbelsäule nur ein schmaler, seichter, etwa $1 \mathrm{~cm}$ tiefer 8paltraum, der von Peritoneum ausgekleidet ist. Um die Durchgängigkeit des Rektums gegen den Anus hin zu prüfen, wird im Colon sigmoideum eine Oeffnung angelegt, durch welche man mit einer Sonde eingeht; dabei stösst man auf einen Widerstand, der schätzungsweise $2 \mathrm{~cm}$ von der äusseren Analanlage entfernt ist. Dieses Analgrübchen, welches genau in der Medianebene gelegen ist, wird mitsamt dem Genitalhöckerchen quadratförmig umschnitten und das so erhaltene Stück zur Paraffineinbettung und zur nachherigen mikroskopischen Untersuchung in Formalin eingelegt. Um die Innenseite der Blase zu verfolgen, wird die ganze Blase in der Medianlinie gespalten. Auf dem Blasengrund gegenüber dem Genitalhöcker findet man eine linsengrosse Gewebsprominenz in der Mukosa, in deren Mitte man mit der Sonde $1 \mathrm{~mm}$ tief eindringen kann (Urethralanlage). An dieser Stelle sind die hintere Blasenwand und die vordere Wand des Rektums miteinander verwachsen, sodass man, wenn man einen Schnitt dureh dieses Grübchen legt, in einer Ebene die Blasenwand mit dem Urethralgrübchen, und das blinde Ende des Mastdarmes erhält (siehe Taf. XV, Fig. 4). 


\section{Brustsektion.}

Der Brustkorb hat eine gedrungene Form. Das Sternum zeigt in der Medianlinie eine starke konvexe Einziehung. Nachdem dasselbe und die vorderen Rippenknorpel entfernt sind, stellt der Brustraum bei angespanntem Diaphragma die Form eines gleichschenkligen Dreiecks dar, dessen Basis $10 \mathrm{~cm}$ und dessen Höhe $3,5 \mathrm{~cm}$ misst. Weder im Pleuraraum noch im Perikard ist eine Flüssigkeitsansammlung vorhanden.

Thymus: klein, von hellroter Farbe, o. B.

Herzmaasse: 2:2:1. Die Gegend des rechten Ventrikels ist plattgedrückt und hat eine Dicke von nur $1 / 2 \mathrm{~cm}$. Aorten- und Pulmonalisstämme getrennt. Klappen o. B. Ductus Botalli und Foramen ovale offen.

Lungen: Beide Lungen sind blattartig, stark nach hinten verlagert, in die unteren Partien papierdünn auslaufend, atelektatisch. Maasse links $3,5: 2,5: 0,5$; rechts $3: 1,5: 0,5$.

\section{Kopfsektion.}

Das rechte Os parietale hat sich in seiner ganzen Ausdehnung. unter den Rand des linken Occipitale, des linken Parietale und Frontale geschoben. Die grosse Fontanelle ist weit offen. Nach Weglösen der Kopfhaut sieht man auf dem oberen Teil des Os parietale und temporale sin. ein subfasziales Hämatom. Beim Durchtrennen der Kopfknochen entleeren sich aus dem Subduralraum im Strahl ca. $20 \mathrm{~cm}$ klarer Flüssigkeit. Die Pia zeigt leichte Gefässinjektion. Auf der Gehirnoberfläche sieht man wenige Gehirnwindungen; Gehirnsubstanz breiartig. Tentorium cerebelli ödematös. Knochen der Schädelbasis weich, mit wenigen ossifizierten Partien.

Um sich ein genaueres Bild über die Art der vorliegenden Missbildung zu verschaffen und eine Vorstellung über die Rückwirkung derselben auf den Organbau und seine Funktionen zu bekommen, wurden alle Organe des Fötus einer mikroskopischen Untersuchung unterzogen.

Bei der Herstellung und Deutung der mikroskopischen Präparate war mir die Hilfe von Dr. P. Kworostanski von grossem Werte, wofür ich auch an dieser Stelle meinen verbindlichsten Dank ausspreche.

Zur besseren Orientierung werden die Stellen, welche für die Erklärung der Missbildung am wichtigsten erschienen, in Textfig. No. 3 durch punktierte Linien angedeutet und das mikroskopische Bild davon in Tafel XIV u. XV wiedergegeben.

Die Härtung der Gewebsstïckchen erfolgte nach vorheriger Sublimatkonservierung in 4 proz. Formalin. Einige Schnitte wurden mit der Gefriermethode behandelt, andere Gewebspartien nach Paraffineinbettung in Serienschnitte zerlegt.

Die Färbungen wurden mit Hämatoxylin-Eosin und nach van Gieson durchgeführt.

\section{Mikroskopischer Untersuchungsbefund.}

Schnittstelle 1 in Textfig. 3 (Gefriermethode) umfasst die Gewebselemente des rechten Blasendivertikels mit makroskopisch sichtbarer Anlage von rechtem Ovarium und Tube und reicht bis in die Rupturstelle in der Blasenwand. Mikroskopisches Bild siehe Taf. XIV, Fig. 1.

Von der dem Blasenlumen zugekehrten Seite haben wir zunächst eine dürftige Mukosasehicht, die nur aus einem stellenweise mehrsehich- 
tigen, kubischen Epithel und wenigen Bindegewebsziigen besteht. Nach oben folgt, etwa bis zur Hälfte der Blasenwand reichend, eine Lage von dünnen Muskelbündeln, die teils parallel zur Blaseninnenfläche, teils schräg und senkrecht zu dieser verlaufen. In dieser Schicht sind zahlreiche Gefässe in Quer- und Längsrichtung und einige Nervenfasern getroffen. Die obere Hälfte der Blasenwand besteht wieder aus Muskelbündeln, die teils parallel zur Blaseninuenfläche, teils schräg und senkrecht zu dieser verlaufen. In dieser Schicht sind zahlreiche Gefässe in Quer- und Längsrichtung und einige Nervenfasern getroffen. Die obere Hälfte der Blasenwand besteht wieder aus Muskelbündeln, die aber ausnahmslos in einer Richtung - parallel zur Blasenwand - angeordnet sind. Oberhalb davon liegt eine dünne peritoneale Decke mit zartem, einreihigem Endothel. Am lateralen Rande des Schnittes, d. h. an der spontanen Rupturstelle der Blase, haben wir die gleichen Gewebsverhältnisse wie in der eben beschriebenen Blasenwand, mit dem Unterschiede jedoch, dass die Muskelbündel viel dünner, mit Blut imbibiert sind und zahlreiche Gewebshämorrhagien enthalten. Die Rupturstelle, die makroskopisch ein durchaus glattes Aussehen zeigt, ist mikroskopisch am Rande zerfasert, die Muskelfasern sind durch ausgedehnte parenchymatöse Blutungen auseinandergedrängt. Die Muskelzellen sind hyalin entartet und entbehren der Kerne; um ihre Natur gegenüber dem faserigen Bindegewebe festzustellen, wurde eine van Giesonfärbung gemacht. An der Oberfläche enthalten diese Schnitte einen peritonealen Ueberzug, dessen Endothelbelag stellenweise fehlt.

Der obere Teil des Blasenperitoneums geht in einen breiten Gewebsvorsprung über, welcher an den Rändern noch seine peritoneale Natur beibehält und in der Mitte durch faseriges Bindegewebe mit vielen Blutgefässen und wenigen vereinzelten Muskelbündeln zu einem soliden Strang verstärkt wird (Hilus ovarii, Fig. 1 o. H.). Das Bindegewebe des Hilus setzt sich als dünne Randbegrenzung auf ein drüsiges epitheliales Gebilde (Ovarium) von ovaler Form ïber. (Tunica albuginea. Taf. XIV, Fig. 1, T. a.) Diese bedeckt jedoch nicht das ganze Orarium, sondern nur die der Tube zugekehrte Seite. Der mittlere Teil des Ovarium wird von grossen epithelialen Zellen mit grossen bläschenförmigen Kernen gebildet, die zwischen dünnen, bindegewebigen Septen gruppenweise angeordnet liegen. (Genitalzellen im Stadium der ersten Wochen der Entwickelung analog den Abbildungen bei Felix [(11), S. 874 und 878].

In einigen Schnitten findet man Zellen, welche grösser als die übrigen sind und einen helleren Kern enthalten (Primordialeier). Diese Zellen sind jedoch nicht mit Follikelepithel umrandet. Beim Gefrierschneiden sind einige Zellgruppen aus ihren Fächern herausgefallen, weshalb man in der Abbildung an solchen Stellen nur leere Lücken sieht. Der obere Teil des Organs ist mit einer Lage kubischen Epithels überzogen, das teilweise auf der Tunica albuginea sitzt, teilweise die bindegewebigen Septen direkt berührt.

-Ausser den zahlreichen Gefässen im Ovarialhilus finden wir hier zwischen den Epithelgruppen im spärlichen Bindegewebe viele Blutgefässe in Stauung. Lateral vom Hilus ovarii setzt sich das Peritoneum in ein zweites, strangförmiges, ovaläres Gebilde fort, welches in der Kuppe ein Lumen mit Mukosa bekleidet und dünnem muskulärem Rande trägt (Tube). Das Peritoneum, das dieses Gebilde überzieht, enthält bei seiner Abgangsstelle von der Blasenwand noch einige dünne Muskel- 
bündel, die in einem zarten, bindegewebigen Stroma liegen. Der übrige Teil dieses Peritoneums ist aus lockerem Bindegewebe zusammengesetzt, mit vielen Gefässen und starken parenchymatösen Blutungen (H.) Die Mukosa der Tube besteht aus einem lockeren, dürftigen Stroma, das nach dem spaltförmigen Lumen zu nur mässig entfaltet ist und einen Ueberzug von niedrigem Zylinderepithel trägt. Die ganze Mukosa ist stark hämorrhagisch infiltriert und nach aussen von einer dünnen Schicht von ringförmiger Muskulatur umgeben.

Schnittstelle 2 in Textfig. 3 (mikroskopisches Bild, Taf. XIV, Fig. 2) durch die linken Adnexe und den Ureter am linken seitlichen Blasendivertikel. Was von der Blasenwand in diesem Schnitt getroffen ist, enthält Mukosa in verschiedener Dicke, stellenweise mit einer beträchtlichen Schicht von Stromazellen und hohem Zylinderepithel, stellenweise mit kaum angedeuteten Mukosaelementen und fehlendem Epithel; dieses ist überhaupt nur in den Vertiefungen der Blasenwand gut zu finden. Der Mukosa folgt nach oben eine Lage von Muskelbündeln, die in allen möglichen Richtungen zur Oberfläche verlaufen. Weiter oben, in lockerem Bindegewebe, liegen vereinzelte Muskellasern und zahlreiche Blutgefässe. Darauf folgt das cystös erweiterte Lumen des linken Ureters mit eigener muskulärer Wand. Die Muskulatur des Ureters besteht aus Bündeln, die schräg und senkrecht zu seinem Lumen verlaufen und dasselbe zirkulär umschliessen. Die Uretermukosa ist nicht in allen ihren Elementen ausgebildet: das Stroma fehlt vollständig; dagegen ist ein einschichtiges, kubisches, abgeplattetes Epithel beinahe in der ganzen Ausdehnung des Lumens vorhanden. In den seitlichen Begrenzungen des Ureters ist die Muskulatur der Blase und des darïberliegenden Peritoneums ziemlich stark verdickt. Die Ureterwand ist nach oben von einer dicken Schicht vom Peritoneum mit Muskelzügen und zahlreichen Gefässen überzogen. Hier geht auf der medialen Seite das Blasenperitoneum z. T. auf ein ovolär drüsiges Organ (linkes Ovarium) über, dessen bindegewebigen Hilus es noch überzieht.

Das Ovarium dieser Seite ist in seinem Bau identisch mit demjenigen rechts, enthält nur in seinem Hilus und im Stroma dieser epithelialen Elemente zahlreiche leere Gefässe. Auf.der lateralen Seite überzieht das Peritoneum mit vielen weiten Gefässen die linke Tube. Der Bau der linken Tube unterscheidet sich von dem der anderen Seite nur durch das Fehlen der Hämorrhagien in der Mukosa und der Stauung in den Gefässen.

Schnittstelle 3 in Textfig. 3 (mikroskopisch nicht gezeichnet, Gefriermethode). Auf der Kuppe des mittleren Abschnittes, am Scheitel der Blase, findet man auf der Innenfläche derselben einen stark papillären Bau. Die Mukosa besteht aus einem einschichtigen Zylinderepithel und einer schmalen Schicht von Bindegewebszellen, der Tunica propria. In den Buchten und Einsenkungen ist dieses Epithel abgeflacht und 2- bis mehrreihig, Auf der Höhe von einigen Papillen ist kein Epithelüberzug vorhanden; die Stromazellen der Mukosa fehlen ganz, ebenso die drüsigen Elemente der Mukosa. Unter der Epithelschicht liegt direkt ein grobfaseriges und zellenreiches submuköses Bindegewebe, dessen Fasern nach allen möglichen Richtungen verlaufen. In der ganzen Ausdehnung desselben sind die Gefässe in Stauung begriffen; daneben findet man diffuse parenchymatöse Blutungen. Dem submukösen Bindegewebe folgt eine Muskulatur in doppelter Lage, zunächst dünne Muskelbündel mit zweierlei Faserverlauf. In der ersten Schicht verlaufen die Fasern 


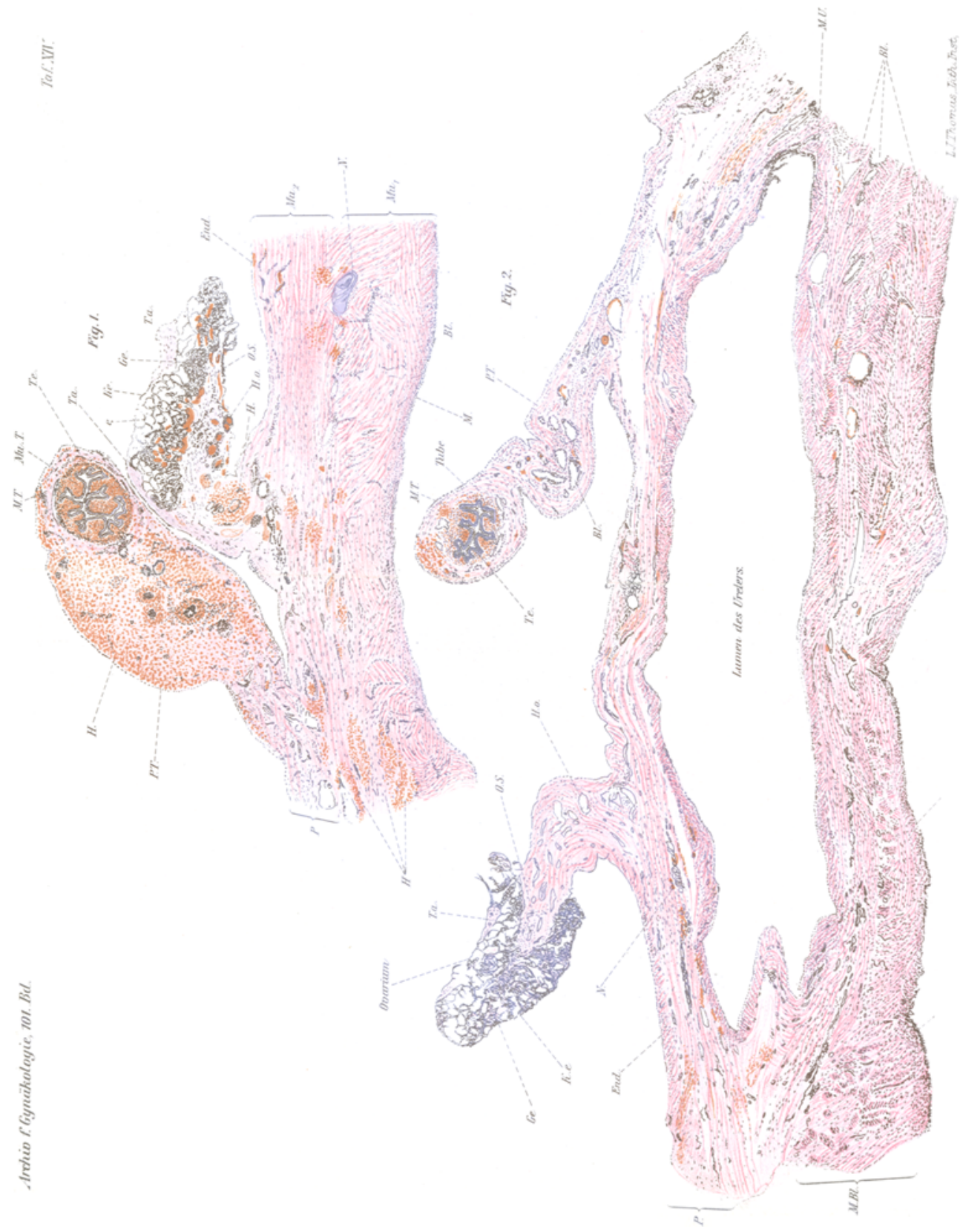


der Mukosa parallel, in der darunterliegenden senkrecht dazu. Auf dieses doppelte Muskelsystem folgt ein weiteres; sehr dickes Lager von breiten Muskelbündeln, eingebettet in einem grobfaserigen intermuskulären Bindegewebe. Auch hier verlaufen die Fasern in allen Richtungen. Unter dieser Schicht, von derselben durch ein stark gewuchertes Bindegewebe getrennt, findet sich eine weitere Lage Muskulatur, deren Bündel senkrecht zur Blasenoberfläche gerichtet sind. Die ganze Muskularis ist gut vaskularisiert.

Die Serosa ist stark verdickt, mit vielen, in Stauung begriffenen Gefässen; das Endothel fehlt im allgemeinen. Vereinzelte Endothelzellen sind nur in den Einbuchtungen erhalten. trophie.

Die ganze Muskulatur macht den Eindruck einer starken Hyper-

Schnittstelle 4 in Textfig. 3 (Gefriermethode, mikroskopisch nicht gezeichnet). Rechtsseitiger Ureter in seinem Verlauf in der Blasenwand. In diesem Präparat ist die ganze Blasenwand des rechten Blasendivertikels getroffen, welche in ihrem Bau nur geringe Abweichungen zeigt von demjenigen des mittleren Blasenvorsprungs: Hier ist das Epithel kubisch, einschichtig auf den Vorsprüngen und mehrschichtig in den Einbuchtungen; im übrigen ist das Verhalten der Mukosa gleich wie oben beschrieben; dagegen ist das submuköse Bindegewebe stärker entwickelt; die Muskulatur ist weniger hypertrophisch, enthält meistens Muskelbündel, deren Verlauf parallel ist zur Blaseninnenfläche. Wenige Bündel, in obige eingeschaltet, haben einen zu diesen senkrechten Verlauf. Die gesamte Dicke der Muskulatur beträgt kaum die Hälfte von der im Schnitt 3 beschriebenen. Lateralwärts wird die Dicke der Muskelschicht allmählich geringer, bis man im faserigen Bindegewebe nur noch vereinzelte Muskelzüge antrifft. Das Verhalten der Mukosa bleibt auch hier unverändert.

In der Mitte des Schnittes, wo die Muskulatur am stärksten entwickelt ist, trifft man, in faseriges Bindegewebe eingebettet, eine schlitzförmige Oeffnung von $7 \mathrm{~mm}$ Länge und $1 \mathrm{~mm}$ Breite mit eigener zirkulärer Muskulatur (Lumen des Ureters). Nach innen zu besitzt der Ureter einen zweireihigen kubischen Epithelüberzug, welcher stellenweise ganz abgestossen ist. Unter dem Epithel liegen Muskelzüge, die innig mit dem faserigen Bindegewebe vermischt sind. Man erkennt diese Muskelfasem nur an der Länge der Kerne; der Faserverlauf ist parallel dem Lumen. Ventralwärts vom Ureterlumen ist die Schicht des Bindegewebes sehr dick (verdicktes Peritoneum), enthält zahlreiche Gefässe und Nervenfasern, längs und quer getroffen. In diesem verdickten Peritoneum findet man wieder, unabhängig von der Muskulatur des Ureters, eigene Muskelzüge und parenchymatöse Hämorrhagien. Die Serosa ist sehr locker, zellarm, enthält nur stellenweise einen Endothelbesatz.

Schnittstelle 5 (in Textfig. 3 nicht eingezeichnet) geht durch den Blasengrund und Beckenboden mit Querschnitt durch das Rektum unmittelbar über seinem blinden Ende (Paraffinmethode).

Makroskopisch findet man, nachdem die Blase aufgeschnitten worden $\mathrm{i}_{\text {st, im Blasengrund eine linsengrosse, seichte Einsenkung, an deren }}$ tiefster Stelle eine kleine, wallartige Verdickung mit Schleimhautüberzug angetroffen wird. Diese Anlage liegt, durch eine $2 \mathrm{~cm}$ dicke Gewebsschicht getrennt, gegenüber dem oben beschriebenen Genitalhöckerchen (siehe Sektionsprotokoll). Links und seitlich von dieser Vertiefang im Blasengrund findet sich das blinde Ende des Rektums. 
Für die Untersuchung wird ein Gewebsstückchen entnommen, welches die beiden letzten Anlagen enthält. Nach Paraffineinbettung wird das Stiick durch Serienschnitte zerlegt, deren Ebenen senkrecht zur Richtung des Rektums stehen. Beim Durchsehen der einzelnen Serienschnitte kann man konstatieren, dass das Lumen des mit Mekonium gefüllten Rektums kaudalwärts allmählich enger wird und schliesslich im Schnitt ganz verschwindet; dass ferner eine Kommunikation des Rektums mit dem Blasenraum nicht besteht, ebensowenig mit dem Anus.

Von diesen Serienschnitten wird derjenige herausgegriffen, dessen Ebene etwa $2 \mathrm{~mm}$ über dem blinden Rektumende liegt und ausserdem die Blase mit der Urethralanlage trifft; in Tafel XV, Fig. 4 ist die mittlere Partie dieses Schnittes abgebildet.

Die gegen den Blasenhohlraum gekehrte Seite enthält als Randbegrenzung in der ganzen Ausdehnung ein teils aus hohen, teils aus abgeplatteten Zellen bestehendes, einreihiges Zylinderepithel. In der Gegend der obenerwähnten trichterförmigen Vertiefung enthält das Gewebe einige papilläre Vorsprünge. Hier ist der Epithelïberzug auf der linken Seite ein mehrschichtiges kubisches Epithel; an der tiefsten Stelle des blindendenden Trichters ist das Epithel wehrreihig. Die obere Reihe ist hoch zylindrisch, das darunterliegende Epithellager kubisch. Auf der rechten Seite des Trichters ist das Epithel wieder einreihig und hochzylindrisch (Anlage der Urethra). Unter der ganzen Epitheldecke verläuft eine Muskelschicht von schräg und senkrecht zur Oberfläche gerichteten Fasern. Dieses Muskellager ist an den seitlichen Partien des Trichters stark entwickelt, wie in der übrigen Blasenwand; dagegen ist an der Spitze des Trichters die Muskulatur nur eine dünne Lamelle. deren Bündel parallel mit dem Epithelrand verlaufen. Unter dieser Muskulatur liegt in der ganzen Ausdehnung des Schnittes eine dicke Schicht von derbfaserigem und faszienähnlichem Bindegewebe, das mit vielen elastischen Fasern durchsetzt ist, und in das zahlreiche Blutgefässe eingelagert sind. In den seitlichen Partien desselben, in gleicher Höhe mit dem Rektum, liegen zahlreiche Nervenfasern und Ganglienzellen (im Bild nicht mehr eingezeichnet). Noch weiter seitlich trifft man lymphatisches Gewebe mit Lymphknötchen.

Links hinten von der Spitze des Epitheltrichters ist in einem Abstand von $6 \mathrm{~mm}$ ein röhrenförmiges Gebilde, das in lockerem Bindegewebe eingebettet ist; die Wand desselben besteht von innen nach aussen aus einer Lage von hohem Zylinderepithel (welches stellenweise fehlt). Diesem folgt eine Schicht von zirkulärer und eine solche von Längsmuskulatur. Das Lumen ist mit einer gelbbraunen Masse und mit abgestossenem Zylinderepithel erfüllt.

In den höhergelegenen Serienschnitten, wo das Lumen des Rektums noch viel grösser ist, ist die Wand des Rektums faltig und hat papilläre Vorsprïnge; die beiden Muskelschichten sind viel stärker entwickelt. In der Nähe derselben findet man Nervenfasern und Blutgefässe; man trifft also in diesen Schnittserien ausser den Gewebselementen der Blase mit Anlage der Urethra und des Rektums auch das Gewebe des Beckenbodens innig mit jenem verwachsen.

Schnittstelle 6 (Paraffinmethode) geht durch die rudimentär angelegten äusseren Genitalien und die Analanlage. Die Höhe des Gewebsstückes beträgt ca. $2 \mathrm{~cm}$. Schnittebenen in frontaler Richtung; mikroskopisches Bild in Tafel XV, Fig. 3).

Auf der Oberfläche ist die Hautanlage leicht wulstig, enthält in 


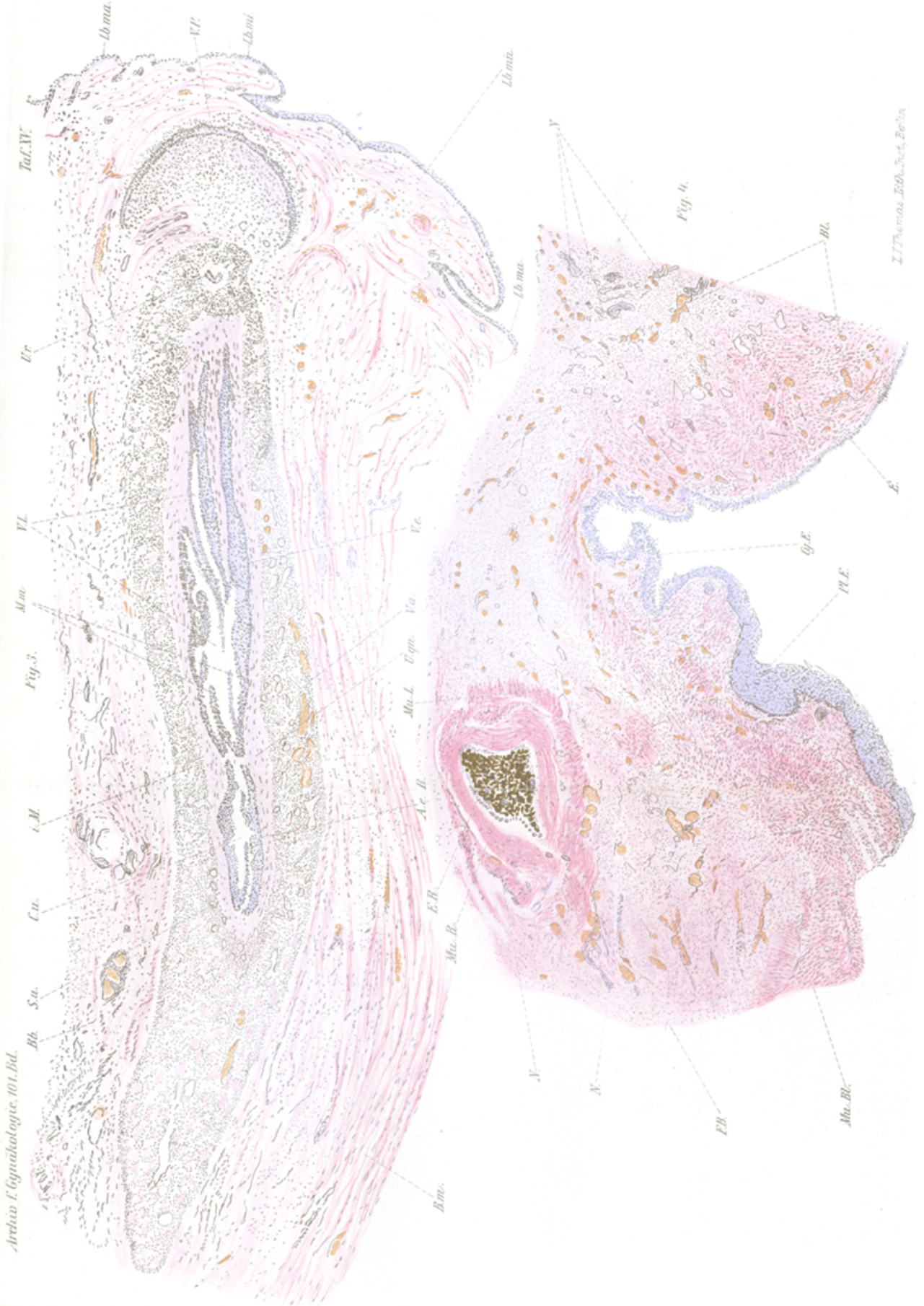


den seitlichen papillären Partien einen Plattenepithelüberzug mit zwei Reihen kubischer Epithelzellen, Lanugohaaren und Talgdrüsen. Der Konfiguration nach entsprechen diese lateralen Wülste den grossen Labien; im zentralen Teil, der wiederum aus Vorsprüngen besteht, ist nur ein Epithelüberzug ohne Haar und Drüsenelemente (Anlage für die Labia minora). Im Zentrum der ganzen Anlage, gegenüber den kleinen Labien, findet sich nahe am Rande ein weiteres, epitheliales, sichelförmiges Gebilde, das aus den gleichen abgeplatteten Zellen besteht wie das Epithel der Labien. Die Konkavität dieser Anlage ist mit lockerem, zellreichem, embryonalem Bindegewebe ausgefüllt (Vaginalpfropf, nach Felix Hymenalanlage?). In den übrigen Serienschnitten kann beobachtet werden, wie diese halbmondförmige Epithelanlage allmählich in den Epithelüberzug der kleinen Labien übergeht.

Der Vaginalpfropf bedeckt den noch nicht formierten Introitus vaginae. Das Vaginalrohr ist als Kanal noch nicht ausgebildet, sondern an seiner Stelle treffen wir einen strangförmigen, längsovalen Gewebskomplex, der aus zellreichem lockerem embryonalem Bindegewebe aufgebaut ist. Inmitten dieser Anlage beginnen sich zwei Hohlräume zu bilden, von denen der eine als primäre Anlage der Vagina, der andere als Cavum uteri betrachtet werden muss. Nach innen sind die Hohlräume mit einem mehrschichtigen kubischen Epithel bedeckt, welchem nach aussen eine dünne Lage von glatten Muskelfasern folgt. Aus der Form der Epithelvorsprünge kann man mit einiger Wahrscheinlichkeit die zukünftige Anlage für die beiden Muttermundslippen erkennen. Von der Kuppe des uterinen Hohlraumes geht ein Epithelzapfen, begleitet von Muskelzellen, nach dem Lumen zu, der wohl als Septum uteri aufgefasst werden darf. Oberhalb der beiden Muttermundslippen treten die seitlichen Muskelfasern zusammen, so dass die beiden genannten Hohlräume entstehen (Verdickung der Muskulatur in der Gegend des inneren Muttermundes). In den anderen Serienschnitten sieht man jedoch, dass das Vaginallumen und die Uterushöhle einen einheitlichen Raum darstellen. Die Uterusanlage besitzt (in allen Schnitten) kein Gebilde, das als Tuben oder Ovarien gedeutet werden könnte. Zwischen Vaginalpfropf und unterem Ende der Vaginalanlage findet sich im genannten embryonalen Bindegewebe eine drüsige Anlage, welche nur in wenigen aufeinanderfolgenden Serienschnitten angetroffen wird und der Form nach eine tubulöse Drüse darstellt (Urethraldrüse?).

Seitlieh vom perivaginalen embryonalen Bindegewebe liegt ringsherum faseriges, lockeres Bindegewebe mit zahlreichen Gefässen und Muskelbündeln (Bindegewebe und Muskulatur des Beckens).

In den tiefer (analwärts) gelegenen Schnitten findet man eine Abzweigung von diesem Komplex embryonalen Bindegewebes, welches als strangförmiges Gebilde gegen den Anus zieht, jedoch kein Lumen und keine Epithelauskleidung enthält (periproktales Bindegewebe). Irgend eine Kommunikation der hier gefundenen Organe mit der in der vorigen Serie von Schnitten erwähnten Urethralanlage (Taf. XV, Fig. 4) ist in keinem Schnitte $\mathrm{zu}$ finden.

Die ganze Anlage der äusseren Genitalien, der Vagina und des Uterus ist noch so weit in der Entwickelung zurückgeblieben, wie die Anlage der genannten Organe bei Felix (S. 898) bei einem Embryo von $26 \mathrm{~mm}$.

Sehnitt 7. Linke Niere (Gefriermethode): Die Nierenkapsel ist mässig dick, besteht aus lockerem, faserigem Bindegewebe mit wenigen 
Kernen. In der Nierenrinde ist das Stroma sehr zahlreich. Darin liegen die Glomeruli mit ihren Gefässschlingen. Das Endothel der Bowmanschen Kapsel ist erhalten. Die Verteilung der Glomeruli in der Rinde ist verschieden; es gibt Partien, wo sehr viele und dichte Reihen von solchen vorhanden sind mit Blutstauung in den Kapillaren; daneben sind Stellen, wo man nicht mehr als 2 Reihen von Glomeruli findet. Ebenso ist die Zahl der Harnkanälchen (der Henle'schen Schleifen) eine verschiedene. Stellenweise sind sie durch stark gewuchertes Bindegewebe zum Schwund gebracht. Die Marksubstanz ist im Verhältnis zur Rinde sehr schmal und enthält in der faserigen Grundsubstanz wenige ungleichmässig verteilte ableitende Harnkanälchen. In ganzer Ausdehnung der Marksubstanz trifft man zahlreiche Hohlräume mit dünner, bindegewebiger Wand und einer Auskleidung von Endothel (erweiterte Venen ohne Blutinhalt). Einige dieser Cystenräume konfluierten miteinander (entstanden durch Blutstauung und Zerreissen der Wände). Die Blutgefässe der Marksubstanz sind von mittlerer Grösse, grösstenteils blutleer; die kleinsten Gefässe sind in Stauung begriffen.

Das Nierenbecken ist im Vergleich zur Breite der übrigen Niere ausserordentlich weit, hat eine dicke, bindegewebige Wand, die stellenweise eine papilläre Ausstülpung zeigt. In den Buchten der Papillen ist das Epithel kubisch, mehrschichtig, sonst einschichtig; im übrigen fehlt der Epithelüberzug ganz.

Schnitt 8: Rechte Niere (Gefriermethode). Der histologische Bau dieser Niere ist ähnlich dem der linken; doch ist in der Rindensubstanz die Zahl der übereinandergereihten Glomeruli grösser und regelmässiger. In der Marksubstanz ist die Wucherung des Bindegewebes viel stärker, ähnlich wie bei entzündlichen interstitiellen Nierenprozessen. Die Cysten in der Marksubstanz sind auch hier vorhanden, doch ist ihre Zahl nicht so gross. Das Lumen der Hohlräume ist grösser als links. Dieselben kommunizieren unter sich und mit dem nur mässig erweiterten Nierenbecken. Die Wand des letzteren ist noch viel dicker als bei der linken Niere. Das Epithel ist einreihig und nur an wenigen Stellen erhalten.

Schnitt 9: Leber (Gefriermethode). Zeichnung der Leberacini wegen Mangels an interlobulärem Bindegewebe nur undeutlich zu erkennen. Die Venae centrales sind dünnwandig, haben ein sehr weites Lumen. An einigen Stellen sind die Gefässe vom Pfortadersystem getroffen; diese besitzen sehr breite, aus lockerem Bindegewebe gebaute Wände und ebenfalls ein weites Lumen, in welchem kernlose und kernhaltige Erythrozyten, Lympho- und Leukozyten aller Art enthalten sind. Die interlobulären Gallengänge zeigen normalen Bau. In mehreren Blutgefässen sind die Erythrozyten gut gefärbt, d. h. gut hämoglobinhaltend, während sie in anderen nur als "Blutschatten" auftreten (Aufhören der Blutzirkulation intra vitam). Manche von diesen schattenförmigen Erythrozyten enthalten braunes Pigment. Sowohl frei im Gefässlumen, wie auch in den Leberbalken findet man Klumpen von gelbbraunem Pigment. Die Kapillaren zwischen den Leberbalken begrenzt von den sichtbaren Kupfer'schen Sternzellen, sind sehr weit und strotzend mit allen Blutelementen gefüllt. Besonders stark sind die Leukozyten und Lymphozyten vertreten (Stauung), von denen einige in Mitosen angetroffen werden. Die Leberzellen sind nicht überall zu Leberbalken organisiert,

Schnitt 10: Lunge (Gefriermethode). Beide Lungen zeigen im 
wesentlichen dieselben Verhältnisse. Die Pleura ist dünn, zart und besteht aus lockerem Bindegewebe, welches breite Septen ins Lungengewebe hineinschickt. An einigen Stellen der Pleura sind diffuse parenchymatöse Blutungelı. Die Lunge selbst ist im Zustand der Atelektase. Die nicht entfalteten Alveolen enthalten ein kubisches Epithel. Die zahlreichen, im Schnitt getroffenen Bronchien besitzen ein hohes Zylinderepithel mit Flimmerbesatz. Der Knorpel in der Wand der Bronchien ist noch embryonaler Natur: die Knorpelzellen sind dreieckig, bindegewebig, liegen vereinzelt in hyaliner Grundsubstanz. Die grossen Gefässe haben ein weites, leeres Lumen. Auch die Kapillaren sind weit und im Zustande der Stauung.

\section{Resumé.}

Fassen wir die Befunde der Sektion und der mikroskopischen Untersuchung zusammen, so lassen sich folgende Ergebnisse aufstellen:

1. Das Peritoneum ist verdickt, zeigt aber nirgends Verwachsungen noch Strangbildungen oder Blutergüsse.

2. Die stark diatierte Harnblase besteht aus drei Divertikeln, wovon das zentrale eine starke Hypertrophie und Hyperplasie seiner Muskelwände aufweist; die seitlichen Divertikel besitzen gleichen Bau wie das zentrale, nur mit dünnerer Muskulatur. Folglich sind alle drei Blasenvorsprünge Teile einer und derselben Harnblase.

3. Die Harnblase ist vorn mit der Bauchmuskulatur innig verwachsen, so dass diese direkt in die Muskulatur der Blase übergeht.

4. Die Blase ist hinten und seitlich von den Bauchwänden und vom Beckenboden noch nicht abgesondert; das Peritoneum geht seitlich von den Bauchwänden direkt auf die Blase über und bedeckt diese vollständig.

5. Auf dem seitlichen rechten Blasendivertikel findet sich eine fünffrankstückgrosse Rupturstelle, durch welche der Blasenraum mit der freien Bauchhöhle kommuniziert.

6. Die Adnexe sind beiderseits von embryonaler Beschaffenbeit, durch das Peritoneum mit der Blasenwand verwachsen und liegen der Blase auf. Fine Uterusanlage ist in der Gegend der beiden Adnexe nicht zu finden.

7. Die Blase, welche den ganzen Beckenraum auskleidet und innig mit der Beckenwand verwachsen ist, besitzt nirgends eine Kommunikation mit der Vagina und den äusseren Genitalien. Im Blasengrund ist eine grübchenartige Epitheleinsenkung (siehe Tafel XV, Fig. 4) als rudimentäre Anlage der Urethra vorhanden. 
8. Die Vagina als Hohlraum ist noch nicht ausgebildet.

9. Das Rektum endet blind im Bindegewebe der Blasenwand, seitlich von der rudimentären Urethralanlage und ohne Kommunikation mit dem Blasenraum.

10. Von den äusseren Genitalien ist im Genitalhöcker nur eine embryonale Anlage der grossen und kleinen Labien, bestehend aus je zwei Hautfalten, zu konstatieren.

11. Unter der äusseren Haut findet sich im lockeren embryonalen Bindegewebe eine fötale Anlage der Vagina und des Uterus, jedoch ohne Adnexe (Tafel XV, Fig. 3). Beide liegen unterhalb und vorn ron der Blase, mit dieser nicht kommunizierend.

12. Die enorm ausgegehnte Harnblase drängt die Anlage der Ureteren und der Adnexe auseinander, d, h. verhindert, dass sich die oberen Enden der Müller'schen Gänge (Tuben) mit den unteren (Corpus uteri und Vagina) vereinigen.

13. Die Anusanlage ist nur im embryonalen, vom Vaginalrohr sich abzweigenden Bindegewebe schwach angedeutet. Ein Kanal wie auch eine epitheliale Auskleidung fehlen vollständig.

14. Die beiden Nieren sind trotz einiger Stauungscystchen in der linken Niere gat entwickelt und funktionsfähig.

15. Die Ureteren, besonders der rechte, sind in den unteren Abschnitten stark dilatiert und münden in die seitlichen Blasendivertikel.

16. Herz und Leber zeigen dem Alter des Kindes entsprechende Entwicklung, sind sonst ohne Anomalien.

Gestütat auf diese Tatsachen erlauben wir uns folgende Fragestellung:

1. Ist das die Flüssigkeit enthaltende Organ wirklich die Harnblase?

2. Welches ist die Entstehung und die Herkunft der Flüssigkeit?

3. Wie wird durch die pathologisch veränderte Harnblase die Entwicklung der benachbarten Organe, speziell der Genitalorgane, beeinflusst?

ad 1. Alle hier festgelegten objektiven anatomischen Befunde sprechen dafür, dass das die Flüssigkeit enthaltende Hohlorgan mit seiner Rupturstelle auf der rechten Seite die fötale, enorm dilatierte und mit seitlichen Divertikeln versehene Harnblase sei. Als Beweis dafür dient ausser dem typischen anatomischen Bau der allgemeine Situs, die Einmündungsstellen der Ureteren in ihre seitlichen Partien und die dadurch geschaffene direkte Verbindung 
mit den Nieren. Eine Verwechslung mit anderen Organen, mit einer erweiterten Kloake oder einem zur Hydrometra dilatierten Uterus oder einem enorm erweiterten Ureter liegt nicht vor, da diese Organe gesondert für sich gefunden wurden. Gegen irgendwelche Cyste im Mesokolon spricht der muskulöse Bau der Wand mit der typischen Mukosa.

ad 2. Die Frage über die Natur und die Herkunft der in der Harnblase und im Abdomen angesammelten Flüssigkeit kann mit ziemlicher Sicherheit beantwortet werden: Kurz nach der Geburt des Kindes wurden aus dem schlaffen Hautsack, in welchem nur noch ganz spärlich Abdominalflüssigkeit vorhanden war, mit einer Pipette ca. $2 \mathrm{ccm}$ derselben, vermischt mit etwas Blut, herausgehoben. (Leider wurde es unterlassen, während der Geburt mehr vom Inhalt des Abdomens aufzufangen.) Nach Eintrocknen der Flüssigkeit im Reagenzglas wurde - von Dr. Herzfeld, Assistenten am chemischen Laboratorium der medizinischen Universitätsklinik Zürich - eine Analyse ausgeführt. Der Rückstand wurde mit physiologischer Kochsalzlösung mit Hilfe eines Glasstabes zerrieben, zentrifugiert, die klare Flüssigkeit abgegossen und zu dieser einige Tropfen Phosphor-Wolframsäure + Salzsäure hinzugefügt, dann mit Alkali versetzt, worauf eine deutliche Blaufärbung auftrat. Diese Reaktion auf Harnsäure kann im Verhältnis zu einer solch geringen Menge des Ausgangsproduktes als stark positiv angesehen werden. (Methode nach E. Herzfeld, Zentralbl. f. innere Med., 1912, 33. Jahrg.) Andere Harnbestandteile konnten wegen der geringen Menge des Untersuchungsmaterials nicht nachgewiesen werden.

Aus dieser chemischen Analyse geht mit deutlicher Bestimmtheit hervor, dass die Flüssigkeit zum grössten Teil aus Urin bestanden haben muss.

Als Quelle für die Flüssigkeit in unserem Falle sind nur zwei Möglichkeiten gegeben: der grösste Teil wird wohl von den fötalen Nieren sezerniert und ein kleinerer von dem pathologisch veränderten Peritoneum geliefert worden sein. Wenn wir die Literatur durchgehen, so finden wir, dass die meisten Autoren ohne weiteres in analogen Fällen die Annahme machten, dass die in der dilatierten Harnblase angestaute Flüssigkeit Harn sei. In allen diesen Fällen handelte es sich um die Blase oder die erweiterten Ureteren als für sich abgeschlossene Gebilde ohne Kommunikation mit anderen Organen. Durch chemische Analyse wurden diese Ver- 
mutungen nur in wenigen Arbeiten sichergestellt, so in den Fällen von Jany (14), Olshausen (23), Walther (25) und Lusk (20). Darüber besteht wohl kein Zweifel, dass die embryonale Niere sekretionsfähig ist. Ueber ihre mehr oder weniger ausgedehnte Tätigkeit während des Intrauterinlebens gehen jedoch die Ansichten noch auseinander. Bei ausgetragenen Kindern findet man in der Harnblase bei gelegentlichen Sektionen meist nur kleine Mengen von Urin (5-20 cem). Nach Browman (6) enthält die Blase normalerweise bei der Geburt 3-4 ecm Urin; ihre Kapazität beträgt $10 \mathrm{ccm}$, kann aber unter Umständen bis auf $100 \mathrm{ccm}$ steigen.

Wieviel rom sezernierten Harn in die Fruchtblase entleert wird, darüber findet man in der Literatur recht verschiedene Meinungen. So nimmt z. B. Klammroth (2) bei einer Fruchtwassermenge von $1877 \mathrm{cem}$ an, dass von der Niere $1200 \mathrm{~g}$ produziert werden. Gusserow (2) berechnet die Produktion der Niere bis zum achten Schwangerschaftsmonat schon auf einen Liter. Hochsinger (13) glaubt, "dass mindestens in der letzten Zeit der Schwangerschaft der fötale Harn die hauptsächlichste Quelle des Fruchtwassers" darstelle. Ahlfeld (2) dagegen schreibt: "Man müsste sich Zwang antun, unter normalen Verhältnissen den fötalen Harn als die Hauptquelle des Fruchtwassers anzusehen." Auch Fehling (10) spricht sich gegen eine regelmässige Sekretionstätigkeit der fötalen Niere aus, die von den Druckverhältnissen im Aortensystem reguliert wird. Am präzisesten findet sich dieser Gedanke ausgedrückt bei Ahlfeld (2), der sich dahin äussert, "dass wahrscheinlich der arterielle Druck beim Fötus so gering sei, dass es nur dann zu einer nennenswerten Sekretion des Urins kommen könne, wenn dieser Druck durch pathologische Verhältnisse abnorm gesteigert werde".

In unserem Fall ist eine abnorme Drucksteigerung gegeben durch ein vollständiges Fehlen der Urethra und der dadurch bedingten Harnstauung in der Harnblase, welche ihrerseits durch ihre pathologische Konfiguration eine Kompression sämtlicher abdominaler Gefässe bewirkte. Dadurch wurde der Blutdruck im gesamten Gefässsystem und also auch in den Nierenarterien erhöht, was notwendigerweise zu einer stärkeren Nierenfunktion Anlass gab. Diese vermehrte den bestehenden Druck in der Blase noch weiter, so dass ein Circulus vitiosus hergestellt wurde, der in der Weise endigte, dass die Elastizitätsgrenze der Blasenwand übersehritten wurde und eine Ruptur in derselben erfolgte. 
ad 3. In Abhängigkeit von der pathologisch missgestalteten Harnblase und der Flüssigkeitsansammlung in ihr und in der Bauchhöhle waren sämtliche inneren Organe mehr oder weniger in Mitleidenschaft gezogen: die Nieren enthielten Staungscystchen und leicht erweiterte Nierenbecken. Die ersteren mit nachgewiesener Endothelbekleidung können wir nach Nieberding (21) auffassen als durch venöse Stauung in den Nieren entstanden infolge einer Drucksteigerung im Gebiete der Vena cava.

Die Ureteren, besonders der linke, zeigten in ihren unteren Partien, speziell in ihrem Verlauf in der Wand der Harnblase, eine cystenartige Erweiterung. Eine Rückstauung des Harnes von der Blase in die Ureteren genügt zur Erklärung dieser cystösen Gestalt der unteren Ureterabschnitte wohl nicht, denn sonst hätte die Dilatation in ganzen Verlaufe des Harnleiters eine gleichmässige sein müssen, und es wäre wohl auch eine Hydronephrose entstanden.

Die Ursache muss eher in einem exzessiven Wachstum der Blasenwand und einem ungleichmässigen Bau des Ureters gesucht werden. Durch erstere wurde die Bildung der beiden seitlichen Divertikel, in welche die Ureteren einmünden, verursacht. Da nun die Blasenwand mit den Ureteren schon weit von ihrer Mündungsstelle entfernt, so innig ineinander verwachsen sind, dass man sie weder makroskopisch noch mikroskopisch von einander abgrenzen kann (Tafel XIV, Fig. 2), so musste bei einem Auseinandergehen der Blasenwand diejenige des Ureters mitgerissen werden. Dadurch wurde die an der Blase anliegende Ureterwand viel dünner als in den oberen Partien, und derselbe Druck, der oben und im Nierenbecken keine Dilatation zustande brachte, genügte hier, um eine cystische Erweiterung zn verursachen.

Kermauner (19) erklärt die Divertikelbildung in der Blase durch exzessives Wachstum einzelner Wandabschnitte. Brow man $(6$, S. 490), führt die Bildung der Blasendivertikel während der Fötalzeit auf die ungleich starke Entwicklung der Blasenmuskulatur hei einem hohen intravesikalen Druck zurück.

Die Wirkung der dilatierten Harnblase auf die Genitalorgane war eine hemmende, sowohl im Zusammentreffen der Enden der Müller'schen Gänge als auch in der embryonalen Ausbildung der Adnexe und indirekt der äusseren Genitalien.

Wir fanden, dass die Adnexe räumlich durch die Blase sehr weit rom Uterus entfernt sind. Die ersteren wurden auf den seitlichen Blasendivertikeln in einem queren Abstand von $13 \mathrm{~cm}$. 
auf dem Peritoneum freiliegend gefunden. Den Uterus und die $\checkmark$ agina traf man als abgeschlossene Gebilde an der vorderen unteren Seite der Harnblase. Nach Felix (11, S. 893), vereinigen sich die oberen Teile der Müller'schen Gänge mit dem Genitalstrang (Anlage des Corpus uteri und der Vagina) bei Embryonen von einer Länge von $50 \mathrm{~mm}$; da im vorliegenden Fall diese Vereinigung ausgeblieben ist, so muss die hemmende Ursache schon vor Ende des 2. Schwangerschaftsmonats eingetreten sein.

Der Grösse nach gehören die Ovarien (Länge $18 \mathrm{~mm}$ ) ebenso in die Entwicklungszeit von 7-8 Wochen. Nach Felix (11, S. 884) ist bei einem Fötus von $50 \mathrm{~mm}$ Sch. St.-L. das rechte Ovarium $19 \mathrm{~mm}$ und das linke $25 \mathrm{~mm}$. In unserem Falle entspricht also auch die Grösse der Ovarien einem Fötus am Ende des 2. Monats.

Dem histologischen Bau nach gehört das Ovarialgewebe ebenfalls in die Zeit, bei der ein Fötus eine Länge von $50-80 \mathrm{~mm}$ erreicht (vgl. histologische Beschreibung der Ovarien).

Die Tuben zeigen allerdings mehr Falten in der Mukosa, als es in den entsprechenden Bildern bei Felix angedeutet ist. Der Uterus zeigt nur beginnende Lichtung. Seine Mukosa ist nicht differenziert, enthält nur einen Epithelbelag und zeigt noch keine quere Fältelung, die nach Felix (\$. 902) auch erst bei Föten von $12 \mathrm{~cm}$ Länge auftritt.

Unter dem Einfluss des Flüssigkeitsdruckes wurde ein ausserordentlich hoher Stand des Diaphragmas und dadurch eine Kompression der mangelhaft entwickelten Lunge und des Herzens bedingt. Ebenso wurde die eingangs beschriebene Form des Beckens verursacht. Unter der Kompression der Aorta und der dádurch hervorgerufenen Stauung hat die Ernährung aller Gewebselemente im Körper gelitten. So fand man eine auffallende Weichbeit der Schädel- und der Skelettknochen neben einem leichten und serösen Oedem am Kopf und in den seitlichen Thoraxpartien.

Was die Aetiologie der mangelhaften Anlage der äusseren Genitalien, des Rektums und des Anus anbetrifft, so kann man diese nicht als Folge der missgestalteten Blase auffassen, sondern muss diese ebenfalls in einer mangelhaften embryonalen Anlage oder Schädigung der Keimblätter suchen.

Als Ursache für den totalen Verschluss der äusseren Genitalien und die abnorme Konfiguration derselben müssen wir nach Kermauner (19) eine Hypertrophie des Mesoderms im Bereiche der Aftermembran annehmen, so dass eine Einstülpung des Ektoderms 
nicht möglich war. Die darüber liegenden Gebilde, die Urethra und das Rektum, sind durch diese Mesodermschicht in ihrem Wachstum gehemmt und retardiert worden, so dass erstere vollständig verschlossen und von der äusseren Genitalanlage entfernt blieb, letzteres sich mit der Analeinsenkung nicht vereinigte.

Die Vergrösserung der Blase mit ihren Divertikelbildungen erklärt Kermauner als eine aktive Hypertrophie und als exzessives Wachstum ihrer Wände.

Dazu kommt im vorliegenden Fall noch eine passive Dilatation der Blase infolge der Urinretention, die bei dem jedenfalls sehr hohen Druck so weit gesteigert wurde, dass auf der rechten Seite die erwähnte Blasenruptur entstand.

Andere Autoren, wie Ahlfeld (3, S. 284) glauben, dass die Grundursache für derartige Missbildungen mit einer Anomalie des Amnions zusammenhänge, vor. allem die Komplikationen, welche mit einer Erkrankung des äusseren Keimblattes in Zusammenhang stehen.

\section{Li t e r a t ur.}

1. Ahlfeld, F., Geburtshindernis durch Erweiterung der Ureteren des Fötus. Dieses Arch. Bd. 4.

2. Ahlfeld, F., 20 Betrachtungen über die Herkunft des Fruchtwassers. Zeitschr. f. Geburtsh. und Gyn. Bd. 69.

3. Ahlfeld, F., Ueber einen Monopus mit vollständigem Mangel der äussern Genitalien und des Afters. Dieses Arch. Bd. 14.

4. Ahlfeld, F., Lehrbuch der Geburtshilfe.

5. Birnbaum, R., Klinik der Missbildungen und kongenitalen Erkrankungen des Fötus.

6. Browman, J., Normale und abnormale Entwicklung des Menschen. 1911.

7. Döderlein, Dieses Arch. Bd. 27. S. 141.

8. Debrunner, A., Berichte und Erfahrungen auf dem Gebiete der Gynäkologie und Geburtshilfe. Frauenfeld 1911.

9. Dührssen, Demonstrationen eines Fötus mit Aszites als absolutes Geburtshindernis. Zeitschr. f. Geburtsh. and Gyn. Bd. 21.

10. Fehling, Dieses Arch. Bd. 11. S: 550.

11. Felix, W., Handbuch der Entwicklungsgeschichte des Menschen.

12. Herzfeld, E., Zentralbl. f. innere Med. 1912. 33. Jahrgang.

13. Hochsinger, Angeborener Defekt des uropoetischen Systems und totaler Fruchtwassermangel. Wiener med. Presse. 1899.

14. Jany, Klinische Beiträge für Gynäkologie von Betschler und Freund. Breslau 1864. S. 240.

15. Jilden, Gerhard, Ein Fall von Geburtshindernis infolge übermässiger Ausdehnung der kindlichen Harnblase mit gleichzeitigem Aszites. Dissert. Freiburg 1890. 
16. Magenau, Friedr., Ein Fall von Geburtserschwerung durch kongenitale Hydronephrose. Dissert. Tübingen 1912.

17. Michelmann, R., Fötale Harnblasendilatation als Geburtshindernis. Dissert. Berlin 1912.

18. Müller, Arthur, Zur Kasuistik der Erschwerung der Geburt durch die Erweiterung der kindlichen Harnblase. Dieses Arch. Bd. 47.

19. Hermauner, Ernst, in Sohwalbe, Die Morphologie der Missbildungen des Menschen und der Tiere. S. 300. Jena 1909.

20. Lusk, Zentralbl. f. Gyn. 1879. S. 123.

21. Nieberding, Münchener med. Wochenschr. 1887. S. 633.

22. Neumann, J., Dystokie infolge abnormer Vergrösserung des kindlichen Bauches. Monatschr. f. Geb. Geburtsh. und Gyn. Bd. 3.

23. Olshausen, Zur Aetiologie der fötalen Peritonitis. Dieses Arch. Bd. 2.

24. Schwyzer, G., Ueber einen Fall von Geburtshindernis, bedingt durch hochgradige Erweiterung der fötalen Harnblase. Dissert. Zürich 1892.

25. Walther, H., Dystokie infolge übermässiger Ausdebnung der fötalen Harnblase. Zeitschr. f. Geburtsh. und Gyn. Bd. 27.

26. v. Winckel, F., Handbuch der Goburtshilfe. 1908. Bd. 2. 3. Teil.

27. Wolff, Br., Zur Kenntnis der Missgeburten mit Erweiterung der fötalen Harnblase. Dieses Arch. Bd. 65.

\section{Erklärung der Abbildungen anf Tafel XIV-XV.}

Figur 1. Schnitt durch die rechten Adnexe und die Blasenwand. Vergrösserung 1:30; Schnittstelle 1 in T'extfig. 3 .

H. = Hämorrhagien, M. = Mukosa der Blase. Mu. = nntere Schioht der Blasenmuskulatur. $\mathrm{Mu}_{2}=$ obere Schicht der Blasenmuskulatur. N. = Nervenfaser. Bl. = Blutgefässe. P. = Peritoneum. End. = Endothel. Ta. a. = Tunica albuginea. Ke. $=$ Koimepithel. Ge. $=$ Genitalzellen. Os. = Ovarialstroma. H. 0 . $=$ Hilus ovarii. T. e. = Tubenepitbel. M. T. $=$ Muskulatur der Tube. S. = Bindegewebige Septen. MuT. $=$ Mukosa der Tube mit Hämorrhagien.

Figur 2. Schnitt durch die linken Adnexe, Ureter und Blasenwand. Vergrösserung ca. 1:20. Schnittstelle 2 in Textfig. 3 .

Mu. = Mukosa. Bl. e. = Blasenepithel. M. Bl. - Muskulatur der Blasenwand. P. = Peritoneum. Bl. = Blutgefässe. M. U. = Muskulatur des Ureters. K. e. = Keimepithel. T. a. = Tunica albuginea. P. T. $=$ Peritoneum der Tube. M. T. $=$ Musknlatur der Tube. Te. $=$ Tubenepithel. N. = Nervenfaser. End. = Endothel. Ge. = Genitalzellen. 0. s. = Ovarialstroma. H. O. $=$ Hilus ovarii.

Figur 3. Schnitt durch die rudimentären äusseren Genitalien, Vagina und Uterus. Vergrösserung $1: 30$.

Lb. mi. = Isabium minus. Lb. maj. = Labium majus mit Haar- 
anlage. V. P. $=$ Vaginalpfropf. Ur. $=$ Urethraldrüse. Va. $=\mathrm{An}-$ lage des Vaginalrohres. V. L. $=$ Vaginallumen. M. m. $=$ Muttermundslippen. i. M. = innerer Muttermund. C. U. = Cavum uteri. S. U. = Septam ateri. Vo. = Vaginalepithel. . U. e. = Uterusepithel. U. $\mathrm{m} .=$ Uterusmuskulatur. B. l. = Beckenbindegewebe. B. $\mathrm{m} .=$ Beckenmuskulatur.

Figur 4. Sehnitt durch die Blasenwand mit Urethralanlage und durch das blinde Ende des Rektums. Vergrösserung 1:30.

R. = Rektum mit Mekonium. F. R. = einschichtiges Zylinderepithel des Rektums. MuR. = ringförmige Muskulatur des Rektums. MuL. = Längsmuskulatur des Rektums. N. = Nervenfaser. F. B. $=$ Faszienbindegewebe. Bl. = Blutgefässe. Mn. Bl. = Muskulator der Blase. Pl. E. = Plattenepithel. Cy. E. = mehrschichtiges Zylinderepithel. I. = einschichtiges Zylinderepithel. 